\title{
In situ gel drug delivery system for periodontitis: an insight review
}

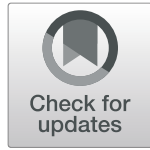

Ravishankar Yadav, Indu Lata Kanwar, Tanweer Haider, Vikas Pandey, Vishal Gour and Vandana Soni*

\begin{abstract}
Background: Periodontitis is a microbial disease that leads to inflammation in the tooth-supporting tissues of the oral cavity that is common among the elderly. It is initiated by oral inflammation induced by bacterial dysbiosis. Choosing an appropriate antimicrobial agent with the right course of drug administration is the key to successful periodontal therapy. In recent times, with more biomarkers and the development of new technologies, several point-of-care testing (POCT) platforms have been developed for the diagnosis and monitoring of periodontitis. This review focuses on oral microbiology and the pathogenesis of periodontitis as well as recent insights into the in situ gel system for periodontitis.

Design: An exhaustive search was conducted in the following scientific databases Science Direct, Springer, Pub Med, and Google Scholar to review all relevant literatures. This is a comprehensive narrative review of the literature, summarizing the perspectives of the authors.

Results: Novel in situ forming gel is introduced at the site that shows a promising potential to overcome one of the main practical obstacles associated with the treatment of local periodontitis: partial adhesion to the surrounding tissue, causing in the accidental expulsion of at least parts of the implants from patient's pockets. This results in a large residence time of the system at the site of action and uncertainty of the final exposure to the drug.

Conclusion: From the reviewed literature, it is concluded that experimental evidence suggests that the in situ gelforming systems can be useful in treating several common diseases of the oral cavity. Future research should focus on clinical studies to be performed for the in situ gel to make a significant contribution to periodontitis.
\end{abstract}

Keywords: Oral microbiology, Periodontitis, Pathogenesis of periodontal diseases, POCT, Biomarkers, In situ gel system

\section{Background}

Periodontitis occurs due to gram-negative [1] anaerobic bacteria and causes inflammation in the disease state of supporting tissue of the teeth [2]. Worldwide, periodontitis is a relatively new inflammatory disease affecting nearly $60 \%$ of the world's elderly population and $50 \%$ of the adult population [3]. It is also associated with the Fusobacterium nucleatum, Porphyromonas gingivalis $(p g)$ [3] "red complex" bacteria, Tannerella forsythia [4], Prevotella intermedia, Actinobacillus actinomycetemcomitans, Treponema denticola, Dialister pneumosintes, Bacteroides forsythus, Capnocytophaga species, and Eikenella

* Correspondence: drvandanasoni@gmail.com

Department of Pharmaceutical Sciences, Dr. Harisingh Gour University, Sagar, Madhya Pradesh 470003, India corrodens [5]. Primary causes of periodontitis are poor oral hygiene, alcohol, stress, tobacco, diet, immune disorders, and systemic diseases. Gram-negative and gram-positive bacteria form a bacterial plaque on supporting tissue of teeth, which increases over a period. These bacteria release collagenases enzymes, antigens, bacterial lipopolysaccharides, endotoxins, ammonia, and hydrogen sulfide. In this response, the flow of gingival crevicular fluid increases in the gingival crevice which carries a large amount of $\beta$ glucuronidase, elastase, prostaglandin, neutrophil, and proteoglycans that are amenable for gingival inflammation [6]. Periodontitis sites are marked by a large volume of inflammatory cell invasion and vascular proliferation [3]. Periodontium supportive collagen is demolished and resorption of alveolar bone begins. Periodontal pockets 
formed due to migration of gingival epithelium along the tooth surface. This provides the perfect environment for the magnification and multiplication of microbes. Figure 1 shows the anatomy of healthy versus pocket formed teeth. In severe stages, it leads to detaching the teeth from the gum and finally loss of teeth [2]. Periodontitis is associated with the development of several systemic diseases such as cancers, atherosclerosis, Alzheimer's disease, diabetes [7], rheumatoid arthritis [4], adverse pregnancy, preterm low birth weight infants [8], cardiovascular diseases [1], stroke, inflammatory bowel diseases, and obesity [9].

The treatment of this chronic infection requires antibacterial medication. Though, it is difficult to achieve an effective concentration of the drug at the sites of microbial infection, periodontal pockets, by the oral administration of commonly used antibiotics [10]. Besides, the distribution of the drug in other tissues and organs associated with frequent oral administration would cause both side effects and antibiotic resistance, especially following long-term therapy. A desirable intra-pocket delivery system should be a low viscosity fluid for better penetration at the sites of infection [11]. The system should also possess good adhesiveness for retention in the periodontal pockets.

Different delivery systems are also available for the treatment of periodontitis such as fibers, stripes, films, and microparticulate systems. But these systems have major disadvantages for example due to the application of fibers, patients experienced discomfort, and at the removal of fiber various degrees of gingival redness [12]. The use of non-biodegradable polymers in stripes and only temporary clinical improvements after the completion of treatment are the major disadvantages of this system. Film thickness and adhesiveness are challenging parameters for preparation, and microparticulate systems have poor retention of the system into periodontal pocket [13]. To overcome these systems, exploitation of polymeric in situ gels for controlled release of various drugs provides several advantages over conventional dosage forms. Sustained and prolonged release of the drug, easily prepared and administered, has good stability and biocompatibility characteristics making the in situ gel dosage forms very reliable. The use of biodegradable and water-soluble polymers for the in situ gel formulations can make them more acceptable and excellent drug delivery systems, and finally they can be rapidly eliminated through normal catabolic pathways that are the major advantages over other delivery systems [14].

In situ forming gel (ISG) appears to be a good candidate to meet the requirements of both low viscosity and superior adhesiveness [15]. Injectable ISG is a particularly effective drug delivery system. Before administration, the in situ forming system is in the form of a sol, and when administered gradually, it becomes a gel or solid depot [16]. ISG is one of the promising local drug delivery systems because it has the potential to maintain high levels of the drug in the gingival crevicular fluid for long periods to gain the desired clinical benefits [6]. It is administered as a precursor that turns into a gel at the sites of action. The phase transition from the solution to the gel is significant to the success of in situ gels for the treatment of periodontitis. Numerous in situ gels, such

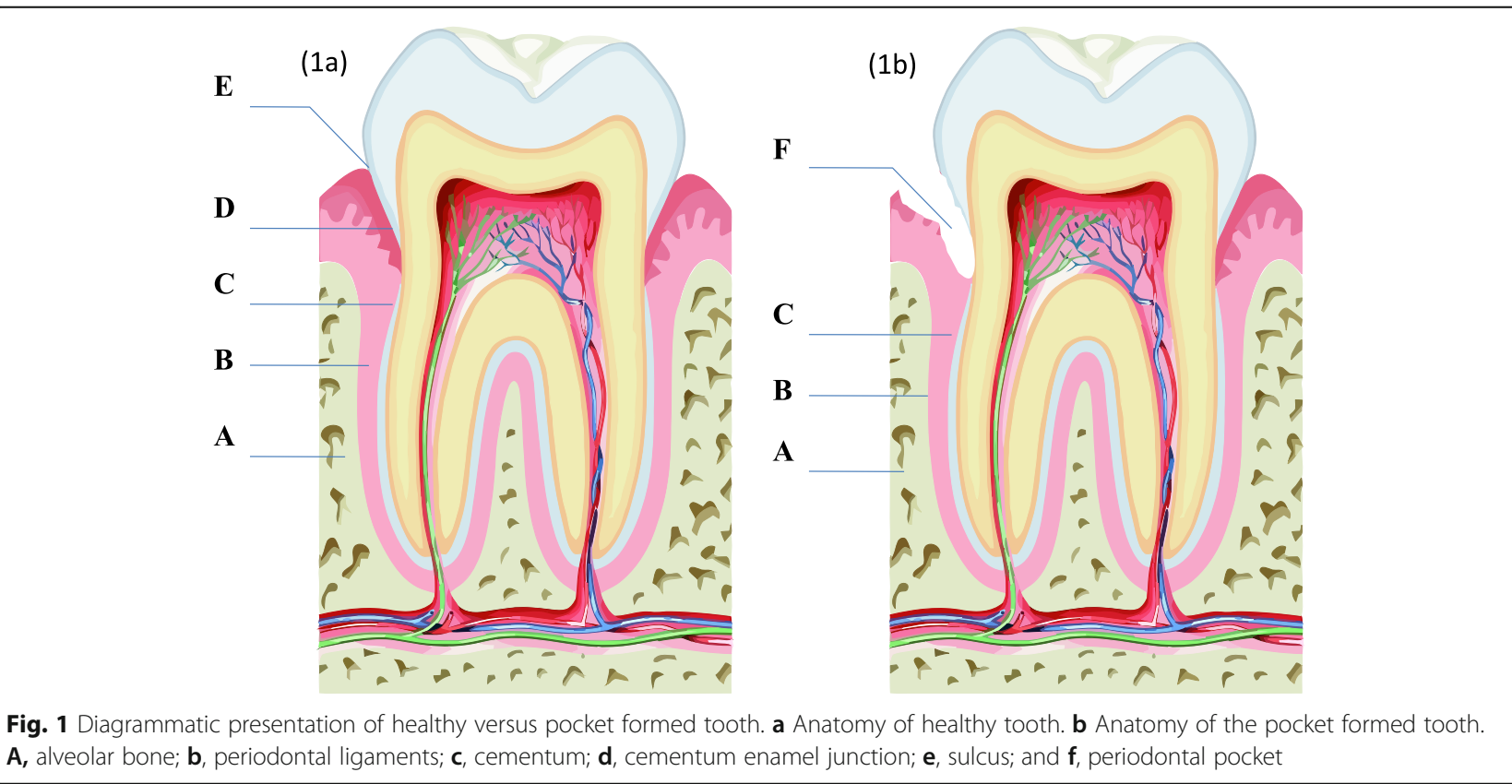


as temperature-sensitive gels, light-responsive, and $\mathrm{pH}$ dependent, have demonstrated the potential to achieve solution-gel transitions in periodontal pockets for adhesion and retention [17].

\section{Main text}

\section{Oral microbiology and pathogenesis}

More than 700 bacterial taxa have been identified to date, which inhabits different niches in the oral cavity by forming biofilms at distinct sites on a tooth (fissures, approximal surfaces, and gingival crevice) and reflects the inherent differences in their anatomy and biology. The oral bacteria have long been considered to be mostly commensal with only a small proportion being pathogenic [18]. The oral microbiome is in continuous interaction with environmental factors and its host [4]. Under homeostatic conditions, the oral microbiome is stable and in symbiosis with its host. However, environmental perturbations can lead to a shift into dysbiotic biofilms which can be a causative factor of dental caries and periodontitis [19]. Periodontal disease is essentially a mixed bacterial infection that produces inflammatory destruction of the tissues that surround and support the teeth. It occurs as a result of a combination of factors, but its primary cause is bacteria found in dental plaque. When left untreated, the disease often causes damage to the affected teeth, accounting for the majority of teeth lost during adulthood. Periodontitis can also cause complete dislocation of the tooth from the socket [20].
In general, anaerobic, gram negative, facultative microorganisms are the main bacteria related to periodontal disease $[2,4]$. It is particularly impossible to prove that the involvement of specific microorganisms causes pathogenesis of periodontitis. Periodontitis bacteria colonize at the gingival crevice and combined with intraperiodontal pockets [2]. The biofilm of plaque is formed at the area of non-self-cleanable. In marginal periodontitis, the biofilm originates from the gingival sulcus, and in the case of advanced periodontal disease, it arises from the gingival pocket [2].

\section{Periodontal pocket}

The formation of periodontal pockets is pathologically dependent on gingival sulcus and is the most important clinical feature of periodontitis. The continuous pocket formation leads to destruction of periodontal supportive tissue, which causes loosening or damage to teeth. Periodontal pocket forms either by microorganisms or their products and causes deepening of the gingival sulcus. The bacterial plaque initiates an inflammatory process in the tissue wall of gingival sulcus and the form pocket. The normal gingival sulcus turns into a pathological periodontal pocket and depends on the number of bacteria present in the dental plaque. The mechanism of periodontitisinduced tooth loss is shown in Fig. 2. The tissues surrounding the gingival, including fibers, are degenerated due to the exudate product of bacterial cells. Collagen fibers can be lost by two mechanisms, either by local

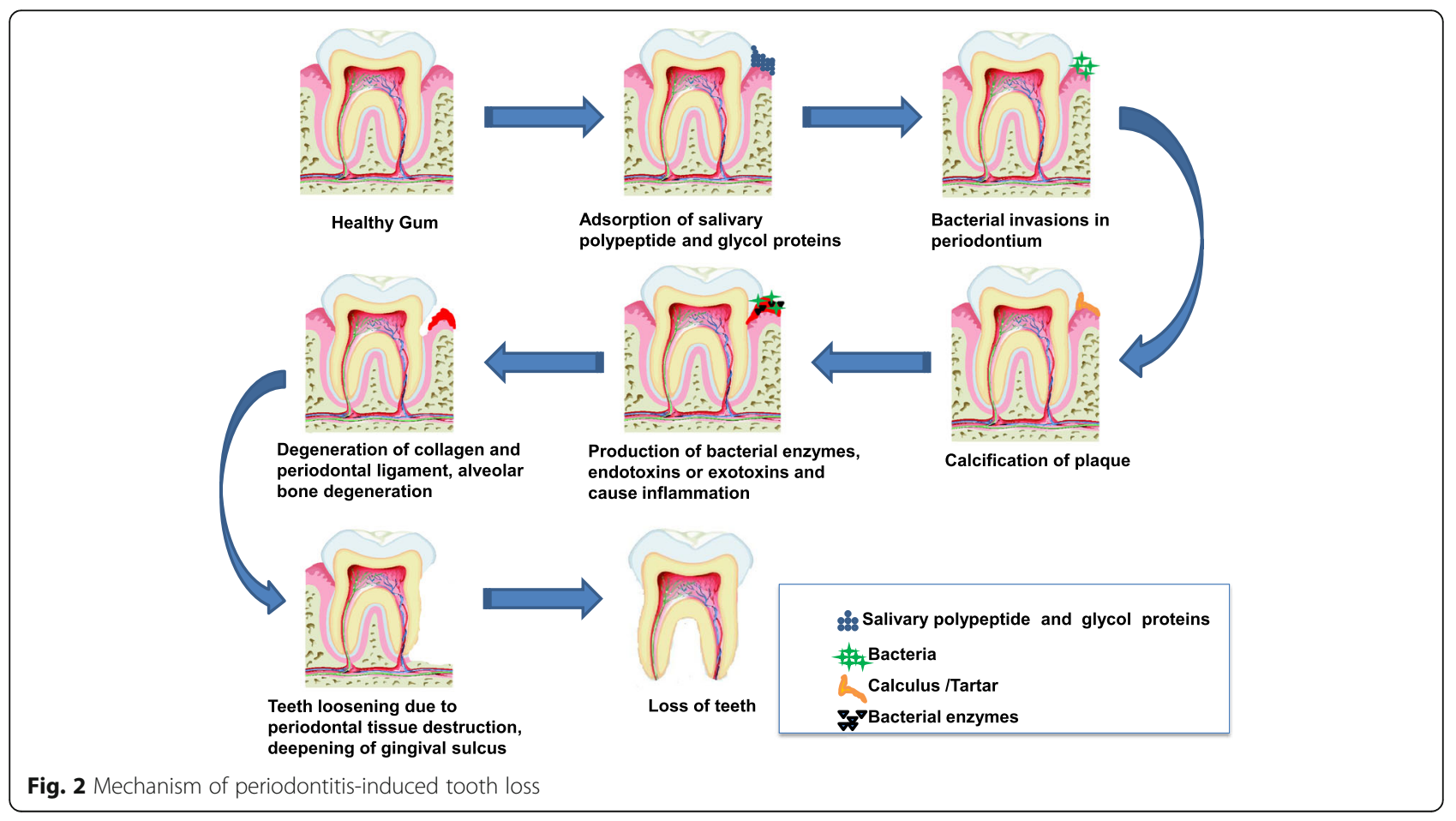


immune response or collagenase and lysosomal enzymes that become extracellular from macrophages and leukocytes at the interface of the ligament and cementum [2].

\section{Periodontitis: types, diagnosis, and treatments Types of periodontitis}

The periodontitis can be classified into two main categories in which one is chronic periodontitis where disease progression occurs slowly to moderate rates [21]. Males and females both are susceptible, while male's susceptibility is more than females for chronic periodontitis [22]. Heavy smokers have a high risk of occurrence of chronic periodontitis [23] due to an elevation of catalase (CAT) enzyme, glutathione peroxidase (GSH-Px), and reduction in superoxide dismutase (SOD) and glutathione levels in gingival tissues [24]. The hypo-oxygenated environment is produced by the smoke components and this favors the growth of anaerobic bacteria which leads to the destruction of tissue due to a reduction in vascular supply [3]. The second one is the aggressive periodontitis (disease progression occurs in rapid rates) occurs in younger individuals (less than 25 years of age) [21]. Depressive mood, weight loss, loss of appetite, and fatigue are strongly related to aggressive periodontitis. The clinical features of aggressive periodontitis included diastema formation with distolabel migration of the incisors, sensitivity due to exposed root, deep dull pain, and periodontal abscess with lymph node enlargement. Women are highly affected by aggressive periodontitis [22]. The periodontitis may classify on the basis of stage, extent and distribution, and grades. The classification of periodontitis is as follows [25]:
Table 1 Tissue destructive biomarkers in periodontitis

\begin{tabular}{|c|c|c|c|}
\hline Classification & Biomarkers & Sample resources & References \\
\hline \multirow{9}{*}{$\begin{array}{l}\text { Biomarkers related to } \\
\text { soft-tissue destruction }\end{array}$} & \multirow[t]{2}{*}{$I L-1 \beta$} & Saliva & {$[27,28]$} \\
\hline & & GCF & {$[29]$} \\
\hline & \multirow[t]{2}{*}{ TNF- $\alpha$} & GCF & {$[29]$} \\
\hline & & Saliva & {$[27]$} \\
\hline & \multirow[t]{2}{*}{ AST } & Saliva & {$[30]$} \\
\hline & & GCF & {$[31]$} \\
\hline & \multirow[t]{2}{*}{ MMP-8 } & GCF & {$[32,33]$} \\
\hline & & Saliva & {$[29]$} \\
\hline & EA & GCF & {$[31,34]$} \\
\hline \multirow{6}{*}{$\begin{array}{l}\text { Biomarkers related to } \\
\text { hard-tissue destruction }\end{array}$} & \multirow[t]{2}{*}{$\mathrm{PGE}_{2}$} & Saliva & {$[27,28]$} \\
\hline & & GCF & {$[35]$} \\
\hline & \multirow[t]{2}{*}{ RANKL } & GCF & {$[36]$} \\
\hline & & Saliva & {$[37]$} \\
\hline & \multirow[t]{2}{*}{ OPG } & GCF & {$[36,38]$} \\
\hline & & Saliva & {$[38]$} \\
\hline
\end{tabular}

1. Stages: based on the severity and complexity of management

Stage I: initial periodontitis

Stage II: moderate periodontitis

Stage III: severe periodontitis with the potential for additional tooth loss

Stage IV: severe periodontitis with the potential loss of dentition

2. Based on the extent and distribution

Table 2 Comparisons of clinical methods and POCT platforms for periodontitis diagnosis [7]

\begin{tabular}{|c|c|c|c|c|c|}
\hline Methods & Inspection & Palpation & Periodontal probing & Radiography & POCT platforms \\
\hline Tools & Naked eye & Hands and tweezers & Various probes & $2 \mathrm{D} / 3 \mathrm{D}$ radiography equipment & $\begin{array}{l}\text { Test kits, LOC/paper- } \\
\text { based platform, } \\
\text { wearable devices }\end{array}$ \\
\hline Detection contents & $\begin{array}{l}\text { Color, shape, and } \\
\text { degree of gingival } \\
\text { recession }\end{array}$ & $\begin{array}{l}\text { The texture of the } \\
\text { gingiva, tooth } \\
\text { mobility }\end{array}$ & $\begin{array}{l}\text { Degree of gingival bleeding, } \\
\text { pocket probing depth, } \\
\text { attachment level }\end{array}$ & $\begin{array}{l}\text { Type and extent of } \\
\text { alveolar bone loss }\end{array}$ & $\begin{array}{l}\text { Biomarkers in saliva, } \\
\text { GCF, and oral rinse }\end{array}$ \\
\hline Parameters & $\begin{array}{l}\text { Gingival index } \\
\text { changes }\end{array}$ & $\begin{array}{l}\text { Gingival texture } \\
\text { and tooth mobility } \\
\text { changes }\end{array}$ & $\begin{array}{l}\text { Degree of bleeding and } \\
\text { extent of soft-tissue } \\
\text { destruction }\end{array}$ & Bone-tissue destruction & Levels of biomarkers \\
\hline Convenience & $\begin{array}{l}\text { Easy for dentists, } \\
\text { difficult for } \\
\text { non-dentists }\end{array}$ & $\begin{array}{l}\text { Easy for dentists, } \\
\text { difficult for } \\
\text { non-dentists }\end{array}$ & $\begin{array}{l}\text { Easy for the dentist and } \\
\text { in-hospital use, difficult for } \\
\text { non-dentist and on-site use }\end{array}$ & $\begin{array}{l}\text { Easy in well-equipped } \\
\text { settings, difficult in } \\
\text { resource-limited settings }\end{array}$ & Mostly easy-to-use \\
\hline Cost & Low & Low & Medium & Medium or high & Low \\
\hline $\begin{array}{l}\text { Prediction in } \\
\text { progression }\end{array}$ & No & No & No & No & Yes \\
\hline
\end{tabular}



a. Localized
b. Generalized
c. Molar-incisor distribution

3. Grades: evidence or risk of rapid progression, anticipated treatment response

a. Grade A: slow rate of progression

b. Grade B: moderate rate of progression

c. Grade C: rapid rate of progression

\section{Diagnosis and treatments}

According to the National Health and Nutrition Examination Survey data, about $11 \%$ of the earth populations are alive with severe periodontitis. Periodontitis has wide-spreading and is related to the development of several systemic diseases. Prevention is better than cure and is beneficial to oral health for the prevention of periodontitis. Proper diagnosis and treatment becomes very important for a patient suffering from periodontitis. Periodontal inspection, probing, palpitation, and radiography (current clinical diagnostic methods) cannot meet the requirements to detect periodontitis. Therefore, there is an urgent need to develop a rapid and costeffective method for diagnosing periodontitis [7]. As a sample source, different biological fluids have been used and in which different types of biomarkers have been evaluated [26]. Biomarkers related to periodontitis can indicate the current severity of the disease [7].

Biomarkers as diagnostic agents The definition of biomarkers as established by the National Institute of

Table 3 Various principle and targets in LOC platforms, paper-based platforms, and chairside platforms for periodontitis diagnosis

\begin{tabular}{|c|c|c|c|c|}
\hline Classification & Principle & Sample & Targets & References \\
\hline \multirow[t]{11}{*}{ LOC platforms } & \multirow[t]{3}{*}{ Electrophoretic immunoassays } & \multirow[t]{3}{*}{ Saliva } & C-reactive protein & \multirow[t]{3}{*}{ [41] } \\
\hline & & & $\mathrm{IL}-6$ & \\
\hline & & & TNF- $\propto$ & \\
\hline & \multirow[t]{3}{*}{ Sandwich ELISA } & \multirow[t]{3}{*}{ Saliva } & C-reactive protein & \multirow[t]{3}{*}[42]{} \\
\hline & & & MMP-8 & \\
\hline & & & $\mathrm{IL}-1 \beta$ & \\
\hline & \multirow[t]{4}{*}{ PCR } & \multirow[t]{4}{*}{ Bacterial culture } & $\mathrm{Pi}$ & \multirow[t]{4}{*}[43]{} \\
\hline & & & $\mathrm{Aa}$ & \\
\hline & & & $\mathrm{Pg}$ & \\
\hline & & & $\mathrm{Td}$ & \\
\hline & Sandwich ELISA & GCF & Calprotectin & [44] \\
\hline \multirow[t]{10}{*}{ Paper-based POCT platforms } & Sandwich ELISA & Subgingival plaque & $\mathrm{Pg}$ & {$[45]$} \\
\hline & Sandwich ELISA & GCF & MMP-8 & {$[46]$} \\
\hline & Sandwich ELISA & Saliva & $\mathrm{Pg}$ & {$[47]$} \\
\hline & Sandwich ELISA & Saliva & MMP-8 & {$[48]$} \\
\hline & \multirow[t]{2}{*}{ Sandwich ELISA } & \multirow[t]{2}{*}{ Saliva } & MMP-8 & \multirow[t]{2}{*}{ [49] } \\
\hline & & & MMP-9 & \\
\hline & Modified Griess reaction & Saliva & Nitrite & {$[50]$} \\
\hline & Proteolytic reaction & Saliva & $\mathrm{Pg}$ & [51] \\
\hline & \multirow[t]{2}{*}{ Proteolytic reaction } & \multirow[t]{2}{*}{ Saliva } & Neutrophil elastase & \multirow[t]{2}{*}[52]{} \\
\hline & & & Cathepsin-G & \\
\hline Chairside platforms & DNA hybridization & Laboratory and clinical specimens & $\mathrm{Aa}, \mathrm{Pg}$ & [53] \\
\hline \multirow[t]{4}{*}{ Microbiological } & Sandwich enzyme immunoassay & Subgingival samples & $\mathrm{Aa}, \mathrm{Pg}, \mathrm{Pi}$ & {$[53,54]$} \\
\hline & BANA hydrolysis reaction & Subgingival plaque & $\mathrm{Pg}, \mathrm{Td}$ & [53] \\
\hline & DNA hybridization & Microbiological samples & $\mathrm{Aa}, \mathrm{Pg}, \mathrm{Td}, \mathrm{Tf}$ & {$[53]$} \\
\hline & Chemical reactions & GCF & Bacterial toxins and proteins & [53] \\
\hline \multirow[t]{3}{*}{ Biochemical } & Enzymatic digestion reaction & GCF & Neutral proteases & [53] \\
\hline & Enzymatic catalysis reaction & GCF & AST & {$[53,55]$} \\
\hline & Sandwich enzyme immunoassay & GCF, saliva & Various related bacterial & {$[56]$} \\
\hline
\end{tabular}


Health. It may be defined as "the biological, biochemical, anthropometric, physiological, etc. characteristics, which are objectively measurable, capable of identifying physiological or pathological processes, or a pharmacological response or a therapeutic intervention" [26]. Periodontitis biomarkers can be detected within $20 \mathrm{~min}$, onsite with the help of POCT. LOC (lab-on a chip), paperbased platforms, and chairside tests are the POCT-based platforms and use in the diagnosis of periodontitis. Lateral flow assay (LFA) and microfluidic paper-based assay device ( $\mu$ PADS) are two main paper-based POCT platforms that have been developed and used.

Biomarkers associated with periodontitis To determine the periodontal sensitivity, specificity, and stages of periodontitis (like occurrence, development, and recovery) numbers of biomarkers have been identified. These biomarkers can be divided into various classes that depend on their sources and related lesions [7]. The details regarding various tissue destructive biomarkers in periodontitis are described in Table 1.

An elevated level of alkaline phosphatase also used as a diagnostic marker for periodontitis associated with postmenopausal women [39]. In aggressive periodontitis, the biomarker 8-hydroxyoxyguanosine (8-OHdG) in saliva can be used to assess the severity [40]. Table 2 showed the comparison of clinical methods and POCT platforms for periodontitis diagnosis, and Table 3 indicates various principles and targets in LOC platforms, chairside platforms, and paper-based platforms for periodontitis diagnosis.

\section{Treatments}

The treatment of periodontitis is very challenging because the distribution of the drug in the periodontal pocket is generally not very noticeable and the flow of the gingival sulcus quickly removes the drug from the site of action [57]. For example, it is possible that material is renewed in a 5-mm deep periodontal pocket 40 times per hour [58]. At present, the conventional nonsurgical periodontal treatment primarily consists of scaling and root planning (mechanical removal of bacteria). Although the geometry of the patient's pocket may be unfavorable for complete removal, it causes patient discomfort, and in various cases, pathogens recolonize cavities after treatment. To minimalize the risk of recurrence of pathogenic microorganisms, it has been proposed to use different antimicrobial agents in combination with root planning [59]. This includes tetracycline, doxycycline, metronidazole, azithromycin, minocycline, and tetracycline hydrochloride [60]. An important challenge in this drug treatment is proper administration. The systemic administration leads to the exposure of drugs to the entire organ, resulting in undesirable side effects, and multiple dose leads to the development of bacterial resistances [61].
Table 4 Various thermosensitive polymers $[67,68]$

\begin{tabular}{|c|c|}
\hline Polymer classes & Examples \\
\hline \multirow[t]{3}{*}{ Polysaccharides } & $\begin{array}{l}\text { Cellulose derivatives (methyl cellulose, } \\
\text { HPMC) }\end{array}$ \\
\hline & Xyloglucan \\
\hline & Chitosan and glycerophosphate \\
\hline \multirow{2}{*}{$\begin{array}{l}\mathrm{N} \text {-isopropylacrylamide } \\
\text { copolymers }\end{array}$} & Poly (N-isopropylacrylamide-co-acrylic acid) \\
\hline & $\begin{array}{l}\text { Poly(N-isopropylacrylamide)/poly (ethylene } \\
\text { oxide) }\end{array}$ \\
\hline Poloxamer systems & Poloxamer188, poloxamer 407 \\
\hline Carbomer & Poly (acrylic acid) \\
\hline $\begin{array}{l}\text { Poly (ethylene oxide)/poly } \\
\text { (D, L-lactic acid-co-glycolic } \\
\text { acid) }\end{array}$ & $\begin{array}{l}\text { Poly (lactic-co-glycolic acid)-poly } \\
\text { (ethylene oxide)-poly (lactic-co-glycolic acid) }\end{array}$ \\
\hline \multirow[t]{2}{*}{ Miscellaneous } & Poly (organophosphazene) derivatives \\
\hline & Poly (1,2-propylene phosphate) \\
\hline
\end{tabular}

Mouthwash does not allow satisfactory concentrations of drug to be reached in periodontal pockets. Local drug delivery systems, releasing the active agent at a controlled rate over a predetermined period directly at the site of action, are currently considered as the most favorable approach. An ideal drug delivery device should exhibit ease of delivery, good retention at the site of administration, and preferably control drug release.

In situ gel system In situ drug delivery systems, offer an interesting potential to overcome this crucial obstacle. These are liquid preparations that can be easily injected into the periodontal pocket and then (after solvent replacement) hardened to form a gel with a custom geometry [62]. The gel in situ remains in the form of a solution under nonphysiological conditions and forms a gel in physiological conditions under the control of stimuli such as $\mathrm{pH}$, temperature, ions, and solvent present in the oral cavity [63, 64]. In situ gel provides the drug release at a controlled rate directly to the target site which reduces side effects, thus improving patient compliance [65]. The main advantages of the implants of formation in situ are as follows: they can easily be injected into periodontal pockets, harden to form a solid implant with

Table 5 Various pH-sensitive polymers [69, 70]

\begin{tabular}{ll}
\hline Polymer classes & Examples \\
\hline $\begin{array}{l}\text { Polymers containing } \\
\text { anionic group }\end{array}$ & $\begin{array}{l}\text { Based on poly (acrylic) acid-like carbapol, } \\
\text { carbomer } \\
\text { Polymers which } \\
\text { polymerized at neutral pH }\end{array}$ \\
$\begin{array}{l}\text { Miscellaneous } \\
\text { Polyvinylacetal, diethylaminoacetate }\end{array}$ \\
$\begin{array}{l}\text { Cellulose acetate phthalate, polymethacrylic } \\
\text { acid, polyethylene glycol, pseudo-latexes, } \\
\text { and latex }\end{array}$ \\
\hline
\end{tabular}


customized geometry, the time-controlled release of drugs, and no need to remove the empty remnants [66].

\section{Various mechanisms for ISG \\ ISG formation due to physiological stimuli}

Temperature triggered ISG systems These systems are injectable liquids that can be provided in the body in a minimally invasive manner before solidifying within the desired tissue, organ, or body cavity [67]. The concept relates to the development of mucoadhesive formulations comprising a temperature-activated solution to gel transition polymer over a temperature range of 25$37^{\circ} \mathrm{C}$. The polymers with a low critical solution temperature of around $32{ }^{\circ} \mathrm{C}$ undergo a phase transition at body temperature. For ISG systems, various thermosensitive polymers may be used shown in Table 4.

pH triggered in situ gelling systems A polymer having a basic group or an acid group is included in the class of $\mathrm{pH}$-sensitive polymers. These types of polymers polymerize during exposure to different physiological/ environmental $\mathrm{pH}$ due to proton acceptance or release. The solution-gel transition occurs due to a change in physiological $\mathrm{pH}$ that forms in situ gel [69]. Numerous $\mathrm{pH}$-sensitive polymers are used in ISG are described in Table 5.

In situ gel formation due to ion-activated system A change in the ionic strength of the instilled solution causes gelation. The gelation rate is determined by the osmotic gradient around the surface of the gel. Change in ionic strength of the instilled solution induces the gelation. The rate of gelation is determined by the osmotic gradient around the surface of the gel. Some electrolytes such as $\mathrm{Ca}^{2+}, \mathrm{Mg}^{2+}$, and $\mathrm{Na}^{+}$cations are present in fluids available in the mouth cavity and play a vital role in the initiation of gelling when the solution introduced into body cavities. Example of polymers: alginates, hyaluronic acid, and gellan gum or gelrite [69].

In situ gel formation due to solvent exchange The gel solidifies due to the solvent exchange taking place with the surrounding aqueous environment.

Swelling It is also one of the important mechanisms to form in situ gel; in this method, material absorbs water, which is available in the surrounding environment and expands to occupy the desired space [69]. An example of such material is glycol monooleate (myverol 18-99), which is lipid and polar. Lyotropic liquid crystalline phase structures form due to swelling of that polar lipids. It has bioadhesive properties and in vivo can be degraded by enzymatic action [71].

Diffusion Drug release from the system follows two mechanisms, namely diffusion, and erosion, of which diffusion is a more reliable and accurate mechanism. Movement of the atom, ions, and molecules from a region of higher concentration to a region of lower concentration is known as diffusion and it is driven

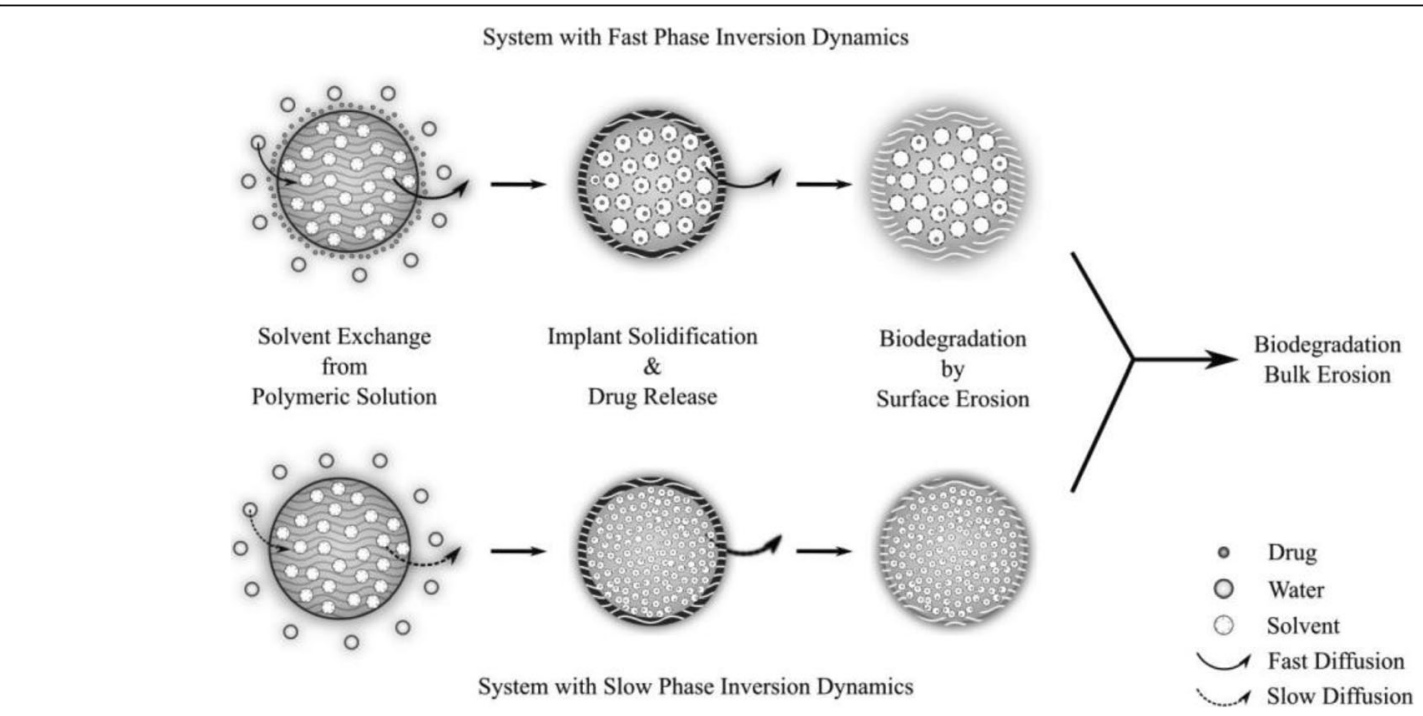

Fig. 3 Mechanism of gel formation and drug release. Reproduced with the permission from Juvekar et al. [6]. Solvent exchange occurs from the polymeric solution. Gel solidification during coagulation of the polymeric solution and simultaneously diffusion of the drug takes place, later than polymeric degradation either by surface erosion or throughout the polymeric matrix system. System with fast phase inversion dynamics implant shows burst release of drug, whereas system with slow phase inversion dynamics, the burst release is not observed 
Table 6 Various in situ gel systems

\begin{tabular}{|c|c|}
\hline Drugs & Polymers/solvents \\
\hline \multicolumn{2}{|l|}{ Temperature-sensitive systems } \\
\hline Moxifloxacin hydrochloride & $\begin{array}{l}\text { Methylcellulose, carbopol 934P, poloxamer } 40 \\
\text { gellan gum }\end{array}$ \\
\hline $\begin{array}{l}\text { Ornidazole and doxycycline } \\
\text { hyclate }\end{array}$ & $\begin{array}{l}\text { Chitosan-vanillin cross-linked polymer, pluroni } \\
\text { F127 (P127) and pluronic F68 (P68) }\end{array}$ \\
\hline
\end{tabular}

Levofloxacin (LVF) and

metronidazole (MZ)

Simvastatin

Curcumin

Levofloxacin and

metronidazole

Articaine hydrochloride
Poloxamer 407, chitosan

Poloxamer 407, methylcellulose

Pluronic F127 (30\% w/v), carbopol P934 (1\% w/ v)

Chitosan

Pluronic F-127, HPMC K-100/carbopol 934P
Result

References

A formulation containing gellan gum $0.245 \% \mathrm{w} / \mathrm{V}$, poloxamer 407 19.072\% w/v shows gelling time $102 \mathrm{~s}$, temperature $36{ }^{\circ} \mathrm{C}$ and drug release $98 \%$ at $9 \mathrm{~h}$

In the treatment of periodontal pocket infection microspheres loaded in situ gel (MLIG) implant gives various desired properties in one system including biodegradability, biocompatibility, stability, syringebility, mucoadhesivity, prolonged release, patients compliant, and cost-effective.

A combination of chitosan $1.5 \% \mathrm{w} / \mathrm{v}$ and poloxamer 407 gives mucoadhesive, thermoresponsive, and controlled release of drugs up to $48 \mathrm{~h}$.

A combination of 25\% poloxamer 407 and 5\% methylcellulose gives thermoresponsive injectable gel at body temperature. It also gives a controlled release of drug up to 10 days.

$1 \%$ w/v of carbopol P934 and 30\% w/v of pluronic F127 give double response ( $\mathrm{pH}$ sensitive and thermoresponsive) in one system.

In the periodontal disease treatment, chitosan is effective as well as is a good carrier for drug delivery.

A combination of articaine hydrochloride ( $4 \% \mathrm{w} / \mathrm{w})$, pluronic F-127 (20\% w/W), and hydroxyl propyl methyl cellulose $(0.1 \% \mathrm{w} / \mathrm{w})$ gives prolonged analgesia or local anesthesia, thermoresponsive, and sustained release of drug respectively.

Solvent exchange systems
Doxycycline hyclate

Doxycycline hyclate

Doxycycline hyclate

Doxycycline hyclate
Chlorhexidinedihydrochloride PLGA, HPMC, N-methyl pyrrolidone

Metronidazole
Eudragid RS, N-methyl pyrrolidone, clove oil

Bleached shellac, agarose, hexane, glyceryl monostearate, dimethyl sulfoxide, $\mathrm{N}$-methyl pyrrolidone, 2-pyrrolidone

Glyceryl monostearate, dimethyl sulfoxide, Nmethyl pyrrolidone, 2-pyrrolidone

Bleached shellac, dimethyl sulfoxide, $\mathrm{N}$-methyl pyrrolidone, 2-pyrrolidone

Glycerol monooleate, N-methyl pyrrolidone
All in situ gel gives their solvent release more than 7 days with release rate order DMSO > NMP > PYR. Among these solvents, PYR is best because drug release is effectively retarded from in situ gel and in situ microparticle due to the high viscosity of bleached shellac in PYR.

Thermal degradation of the polymer could delay, due to their high intermolecular strength. In situ microparticles of glyceryl monostearate with DMSO give delayed thermal degradation.

By dissolving of bleached shellac in dimethyl sulfoxide, NMP, PYR, and in a eutectic mixture, in situ forming gels can be prepared. The result was as follows: viscosity, eutectic mixture $>$ PYR $>$ DMSO $>$ NMP and velocity of gel formation, DMSO $>$ NMP $>$ PYR $>$ eutectic mixture. Slow exchange of solvent and highest degradation was the problems with the PYR solvent. Preparation of eutectic mixture cannot be given by needles due to their high apparent viscosity.

The addition of clove oil retarded the solvent exchange and prolonged the release of doxycycline hyclate from Eudragid RS in situ gel. When the amount of Eudragid RS was increased then the transformation of liquid to gel was more rapid during in vitro testing.

Loss of formulation accidentally from gingival pockets can be reduced in comparison with available commercial products in the market.

In the treatment of CP (chronic periodontitis), reduced side effects and enhanced bioavailability achieved by using the intra pocket system of lyotropic liquid 
Table 6 Various in situ gel systems (Continued)

\begin{tabular}{lll}
\hline Drugs & Polymers/solvents & Result \\
\hline Doxycycline hyclate & $\begin{array}{c}\text { crystal. } \\
\text { Bulfoxide, 2-pyrrolidone, glyceryl monostearate }\end{array}$ & $\begin{array}{l}\text { P. gingivalis, S. aureus, and S. mutans are effectively } \\
\text { inhibited by doxycycline hyclate-loaded bleached shel- } \\
\text { lac in situ microparticles. And it gives sustained drug } \\
\text { release for a period of 40 days in vitro with a Fickian } \\
\text { diffusion mechanism. }\end{array}$
\end{tabular}

References

\section{pH-responsive systems}

Doxycycline

Curcumin

Secnidazole,

serratiopeptidase

lon-activated system

Metronidazole

Gellan gum, thioglycolic acid

Doxycycline HCL

Sodium alginate, HPMC, mannuronic acid,

guluronic acid, human serum with calcium

Polyethylene glycol (PEG) 400, sodium lauryl sulfate (SLS), tri-ethanol amine (TEA), pluronic

127, carbopol P 934, propylene glycol (PG)

Alginate/HPMC, propylene glycol

a-methoxy- $\omega$-amino-poly (ethylene glycol), N, N, dimethylformamide (DMF)

Carboxymethyl chitosan (CMCS), chitosan glycidyl methacrylate dimethyl sulfoxide (DMSO)

\section{Redox in situ gel system}

PEG possessing sulfanyl groups at both ends (SHPEG-SH), methanol and chloromethyl styrene (CMS)
Mineralized doxycycline nanoparticles manufactured with block copolymer that provides drug release with $\mathrm{pH}$ sensitivity. Template mineralized with calcium carbonate. At normal pH of gingival drug release from nanoparticles retarded due to mineral structure, but in acidic $\mathrm{pH}$ of gingiva which occurs due to bacterial biofilm provides controlled release of antibiotics.

$1 \% \mathrm{w} / \mathrm{V}$ of carbopol P 934 and $30 \% \mathrm{w} / \mathrm{v}$ of pluronic F127 give a double response ( $\mathrm{pH}$ sensitive and thermoresponsive) in one system. The formulation which contains $2 \%$ curcumin gives the most accepted results related to $\mathrm{pH}$, gelling temperature, and controlled release of drugs for long periods.

In situ gel system formulated by using alginate with hydroxyl propyl methyl cellulose and secnidazoleserratiopeptidase, which provides controlled release of drugs for more than $10 \mathrm{~h}$

Esterification of gellan gum with thioglycolic acid provides thiol conjugation. Conjugation of gellanthioglycolic acid characterized by decreased sensitivity of gellan gum to cation-activated gelation. And mucoadhesive property increased due to thiolation.

The formulation consists of alginate and HPMC with the function of gel former and viscosity enhancer respectively. A similar composition to GCF, that is serum, provides sol-gel phase transformation upon mixing. The formulation provides sustained drug release over a period of 12 days.

Developed a system with biodegradable polymer and photo-initiator: visible light lamp (420-480 nm). The gelation time of formulation decreased by photoinitiator.

\section{Saita et al. successfully developed a redox injectable gel and applied it to the rat associated with periodontitis. And the result was sustained release of drug from the gel, oxidative damage reduced in periodontal area, and gingival blood flow recovery, which was due to ROS scavenging activity of redox injectable gel in the periodontal area. Additionally, $P$. gingivalis inhibited by RIG and bone loss prevented.}

depends on the pore formation process during the phase inversion. The diffusion of the drug takes place during the coagulation of the polymeric solution. Erosion is the phase of drug release seen during the polymeric degradation where the molecular weight of the polymer gradually reduces over $15 \mathrm{kDa}$. Polymer

erosion is observed either over the surface or by a concentration gradient. In situ gel formation which is based on the diffusion method, polymer matrix precipitated because solvent diffuses from polymer to surrounding tissue (Fig. 3) [72]. An example of a solvent that is useful for such system is $\mathrm{N}$-methyl pyrrolidine [69]. Diffusion is dependent on the porosity of the polymer matrix, which eventually 
throughout the polymeric matrix system [17]. Overall, the drug release from a solid implant may occur by the diffusion of the drug through water-filled pores, by the erosion of the implant or by osmosis. The sudden drug release observed in the lag period between administration of the formulation and further solidification of the implant is the burst release. It is seen due to the phase inversion dynamics taking place between the polymeric solution and the aqueous environment. A controlled burst release, however, can be beneficial in certain ISG to obtain a steady-state profile. A highly miscible solvent shows fast diffusion of the solvent in the aqueous environment. This system shows the burst release of the drug. The resultant implant further has large pores from where the drug release is immediate. In the case of solvents with low water miscibility, the burst release is not observed due to slow phase inversion dynamics. The implant has fine pores that extend the drug release still further. The biodegradation of the system is slow as compared to the implant formed by fast diffusion of the solvent [73].

\section{In situ gel formation due to photopolymerization} Photopolymerization is commonly used to form biomaterials in situ. A mixture of monomer and photoinitiator get polymerized at long ultra violet (UV)-visible wavelengths [69]. The long UV-visible wavelengths are preferred for the photopolymerization. Generally, short UV-visible wavelengths are not used because it biologically harm and can limit penetration of tissue [71]. Acrylates are commonly used as polymerizable groups because photopolymerization occurs rapidly with rapid photo-initiators. Dimethoxy-2 phenylacetophenone and camphorquinone act as photo-initiators for UVphotopolymerization and visible-photopolymerization, respectively [71]. Various in situ gel drug delivery systems based on various triggered systems are described in Table 6.

\section{Conclusion}

The injectable in situ gel formation system offers the remarkable potential for the treatment of periodontitis, which allows the controlled release of drugs regarding site-specific management. The in situ injection gel formation system offers great potential for the treatment of periodontitis, allowing the timing of drug release to be controlled based on the treatment of the particular site. They are intensively sticking to teeth' surfaces and provide adequate mechanical strength to assure reliable and prolonged residence times in periodontal pockets. The spotlight is likely to remain on the in situ gel-forming system with an array of polymers that have synergistic action in optimally combating and reversing the periodontal. This summarizes the state-of-the-art technology of local periodontal therapy. The focus in the coming years should be on in vivo profiling of these systems.

\section{Abbreviations \\ POCT: Point-of-care testing platforms; ISG: In situ forming gel; CAT: Catalase enzyme; GSH-Px: Glutathione peroxidase; SOD: Superoxide dismutase; LOC: Lab-on a chip; 8-OHdG: 8-hydroxyoxyguanosine; IL-1 1 : Interleukin 1 beta; TNF- $\alpha$ : Tumor necrosis factor alpha; AST: Aspartate Aminotransferase; MMP-8: Metalloproteinase-8; EA: Elastase; PGE2: Prostaglandin E2; RANK $\mathrm{L}$ : Receptor activator of nuclear factor kappa-B ligand; OPG: Osteoprotegerin; GCF: Gingival crevicular fluid; PCR: Polymerase chain reaction; ELISA: Enzyme- linked immunosorbent assay; LFA: Lateral flow assay; MPADS: Microfluidic paper-based assay device; Pi: Prevotella intermedia; Aa: Actinobacillus actinomycetemcomitans; Pg: Porphyromonas gingivalis; Td: Treponema denticola; Tf: Tannerella forsythia}

\section{Acknowledgements}

One of the authors, Ravishankar Yadav, gratefully acknowledges All India Council for Technical Education, New Delhi, India, for financial support (GPAT fellowship).

\section{Authors' contributions}

RY, ILK, TH, and VS prepared the preliminary draft for the manuscript. RY, ILK, $T H, V P$, and VG contributed to the writing of the manuscript. VS, TH, RY, and ILK jointly developed the structure and arguments for the paper. TH, VP, and VS made critical revisions and approved the final version of the paper. All authors reviewed and approved the final manuscript.

\section{Funding}

This work did not receive any specific grant from funding agencies in the public, commercial, or not-for-profit sectors.

Availability of data and materials

Data and material are available upon request.

Ethics approval and consent to participate

Not applicable

\section{Consent for publication}

Not applicable

\section{Competing interests}

The authors declare that they have no competing interests.

Received: 14 April 2020 Accepted: 2 July 2020

Published online: 17 July 2020

References

1. Jain N, Jain GK, Javed S, labal Z, Talegaonkar S, Ahmad FJ et al (2008) Recent approaches for the treatment of periodontitis. Drug Discov Today 13(21-22):932-943. https://doi.org/https://doi.org/10.1016/j.drudis. 2008.07.010

2. Vyas SP, Sihorkar V, Mishra V (2000) Controlled and targeted drug delivery strategies towards intraperiodontal pocket diseases. J Clin Pharm Ther 25(1): 21-42. https://doi.org/https://doi.org/10.1046/j.1365-2710.2000.00261.x

3. Banjar W, Alshammari MH (2014) Genetic factors in pathogenesis of chronic periodontitis. J Taibah Univ Med Sci 9(3):245-247. https://doi.org/https://doi. org/10.1016/j.jtumed.2014.04.003

4. Hajishengallis $G$ (2014) Immunomicrobial pathogenesis of periodontitis: keystones, pathobionts, and host response. Trends Immunol 35(1):3-11. https://doi.org/https://doi.org/10.1016/j.it.2013.09.001

5. Oh TJ, Eber R, Wang HL (2002) Periodontal diseases in the child and adolescent. J Clin Periodontol 29(5):400-410. https://doi.org/https://doi.org/ 10.1034/j.1600-051x.2002.290504.x

6. Juvekar S, Kathpalia H (2017) Solvent removal precipitation based in situ forming implant for controlled drug delivery in periodontitis. J Control Release 251:75-81. https://doi.org/https://doi.org/10.1016/j. jconrel.2017.02.022 
7. He W, You M, Wan W, Xu F, Li F, Li A (2018) Point-of-care periodontitis testing: biomarkers, current technologies, and perspectives. Trends Biotechnol 36(11):1127-1144. https://doi.org/https://doi.org/10.1016/j. tibtech.2018.05.013

8. Komine-Aizawa S, Aizawa S, Hayakawa S (2019) Periodontal diseases and adverse pregnancy outcomes. J Obstet Gynaecol Res 45(1):5-12. https://doi. org/https://doi.org/10.1111/jog.13782

9. Botelho J, Machado V, Mascarenhas P, Rua J, Alves R, Cavacas MA et al (2018) Stress, salivary cortisol and periodontitis: a systematic review and meta-analysis of observational studies. Arch Oral Biol 96:58-65. https://doi. org/https://doi.org/10.1016/j.archoralbio.2018.08.016

10. Aminu N, Chan SY, Yam MF, Toh SM (2019) A dual-action chitosan-based nanogel system of triclosan and flurbiprofen for localised treatment of periodontitis. Int J Pharm 570:118659. https://doi.org/https://doi.org/10. 1016/j.jpharm.2019.118659

11. Fernandes T, Bhavsar C, Sawarkar S, D'Souza A (2018) Current and novel approaches for control of dental biofilm. Int J Pharm 536(1):199-210. https://doi.org/https://doi.org/10.1016/j.jpharm.2017.11.019

12. Joshi D, Garg T, Goyal AK, Rath G (2016) Advanced drug delivery approaches against periodontitis. Drug Deliv 23(2):363-377. https://doi.org/ https://doi.org/10.3109/10717544.2014.935531

13. Schwach-Abdellaoui K, Vivien-Castioni N, Gurny R (2000) Local delivery of antimicrobial agents for the treatment of periodontal diseases. Eur J Pharm Biopharm 50(1):83-99. https://doi.org/https://doi.org/10.1016/s09396411(00)00086-2

14. Beg S, Dhiman S, Sharma T, Jain A, Sharma RK, Jain A et al (2020) Stimuli responsive in situ gelling systems loaded with PLGA nanoparticles of moxifloxacin hydrochloride for effective treatment of periodontitis. AAPS PharmSciTech 21(3):76. https://doi.org/https://doi.org/10.1208/s12249-0191613-7

15. Kulkarni AP, Khan SKA, Dehghan MH (2012) Evaluation of polaxomer-based in situ gelling system of articaine as a drug delivery system for anesthetizing periodontal pockets-an in vitro study. Indian J Dentistry 3(4): 201-208. https://doi.org/https://doi.org/10.1016/j.ijd.2012.07.006

16. Yadav SK, Khan G, Bansal M, Thokala S, Bonde GV, Upadhyay M et al (2018) Multiparticulate based thermosensitive intra-pocket forming implants for better treatment of bacterial infections in periodontitis. Int J Biol Macromol 116:394-408. https://doi.org/https://doi.org/10.1016/j.ijbiomac.2018.04.179

17. Swain GP, Patel S, Gandhi J, Shah P (2019) Development of moxifloxacin hydrochloride loaded in-situ gel for the treatment of periodontitis: in-vitro drug release study and antibacterial activity. J Oral Biol Craniofac Res 9(3): 190-200. https://doi.org/https://doi.org/10.1016/j.jobcr.2019.04.001

18. Dewhirst FE, Chen T, Izard J, Paster BJ, Tanner AC, Yu WH et al (2010) The human oral microbiome. J Bacteriol 192(19):5002-5017. https://doi.org/ https://doi.org/10.1128/JB.00542-10

19. Hickey NA, Whitehead KA, Shalamanova L, Butler JA, Taylor RL (2019) A novel microbiological medium for the growth of periodontitis associated pathogens. J Microbiol Methods 163:105647. https://doi.org/https://doi.org/ 10.1016/j.mimet.2019.105647

20. Fernandes T, Bhavsar C, Sawarkar S, D'souza A (2018) Current and novel approaches for control of dental biofilm. Int J Pharm 536(1):199-210

21. Kumar S (2019) Evidence-based update on diagnosis and management of gingivitis and periodontitis. Dent Clin N Am 63(1):69-81. https://doi.org/ https://doi.org/10.1016/j.cden.2018.08.005

22. Ababneh KT, Taha AH, Abbadi MS, Karasneh JA, Khader YS (2010) The association of aggressive and chronic periodontitis with systemic manifestations and dental anomalies in a jordanian population: a case control study. Head Face Med 6(1):30. https://doi.org/https://doi.org/10. 1186/1746-160X-6-30

23. Khan S, Khalid T, Awan KH (2016) Chronic periodontitis and smoking. Prevalence and dose-response relationship. Saudi Med J 37(8):889-894. https://doi.org/https://doi.org/10.15537/smj.2016.8.14223

24. Trivedi S, Lal N (2017) Antioxidant enzymes in periodontitis. J Oral Biol Craniofac Res 7(1):54-57. https://doi.org/https://doi.org/10.1016/j.jobcr.2016. 08.001

25. Caton JG, Armitage G, Berglundh T, Chapple ILC, Jepsen S, Kornman KS et al (2018) A new classification scheme for periodontal and peri-implant diseases and conditions - introduction and key changes from the 1999 classification. J Clin Periodontol 45(Suppl 20):S1-S8. https://doi.org/https:// doi.org/10.1111/jcpe.12935
26. González-Ramírez J, Serafín-Higuera N, Concepción Silva Mancilla M, Martínez-Coronilla G, Famanía-Bustamante J, Laura López López A (2020) Use of biomarkers for the diagnosis of periodontitis Periodontal Disease Diagnostic and Adjunctive Non-surgical Considerations. IntechOpen. p

27. Ebersole JL, Schuster JL, Stevens J, Dawson D, Kryscio RJ, Lin Y et al (2013) Patterns of salivary analytes provide diagnostic capacity for distinguishing chronic adult periodontitis from health. J Clin Immunol 33(1):271-279. https://doi.org/https://doi.org/10.1007/s10875-012-9771-3

28. Sánchez GA, Miozza VA, Delgado A, Busch L (2013) Salivary IL-1 $\beta$ and PGE 2 as biomarkers of periodontal status, before and after periodontal treatment. J Clin Periodontol 40(12):1112-1117. https://doi.org/https://doi.org/10.1111/ jcpe. 12164

29. Shimada Y, Tabeta K, Sugita N, Yoshie H (2013) Profiling biomarkers in gingival crevicular fluid using multiplex bead immunoassay. Arch Oral Biol 58(6):724-730. https://doi.org/https://doi.org/10.1016/j.archoralbio.2012.11. 012

30. Luke R, Khan SN, Iqbal PS, Soman RR, Chakkarayan J, Krishnan V (2015) Estimation of specific salivary enzymatic biomarkers in individuals with gingivitis and chronic periodontitis: a clinical and biochemical study. J Int Oral Health 7(9):54-57

31. Ito H, Numabe $Y$, Sekino S, Murakashi E, Iguchi H, Hashimoto S et al (2014) Evaluation of bleeding on probing and gingival crevicular fluid enzyme activity for detection of periodontally active sites during supportive periodontal therapy. Odontology 102(1):50-56. https://doi.org/https://doi. org/10.1007/s10266-012-0090-1

32. Leppilahti JM, Hernandez-Rios PA, Gamonal JA, Tervahartiala T, BrignardelloPetersen R, Mantyla P et al (2014) Matrix metalloproteinases and myeloperoxidase in gingival crevicular fluid provide site-specific diagnostic value for chronic periodontitis. J Clin Periodontol 41(4):348-356. https://doi. org/https://doi.org/10.1111/jcpe.12223

33. Baeza M, Garrido M, Hernandez-Rios P, Dezerega A, Garcia-Sesnich J, Strauss F et al (2016) Diagnostic accuracy for apical and chronic periodontitis biomarkers in gingival crevicular fluid: an exploratory study. J Clin Periodontol 43(1):34-45. https://doi.org/https://doi.org/10.1111/jcpe.12479

34. Gul SS, Douglas CW, Griffiths GS, Rawlinson A (2016) A pilot study of active enzyme levels in gingival crevicular fluid of patients with chronic periodontal disease. J Clin Periodontol 43(8):629-636. https://doi.org/https:// doi.org/10.1111/jcpe.12568

35. Kumar AK, Reddy NR, Babu M, Kumar PM, Reddy VS, Chavan CV (2013) Estimation of prostaglandin E2 levels in gingival crevicular fluid in periodontal health, disease and after treatment. Contemp Clin Dent 4(3): 303-306. https://doi.org/https://doi.org/10.4103/0976-237X.118354

36. Ozden FO, Sakallioglu EE, Demir E, Bilgici B, Tuncel OK, Gokosmanoglu F et al (2017) Effect of bisphosphonate as an adjunct treatment for chronic periodontitis on gingival crevicuar fluid levels of nuclear factor-kappaB ligand (RANKL) and osteoprotegerin in postmenopausal osteoporosis. J Oral Sci 59(1):147-155. https://doi.org/https://doi.org/10.2334/josnusd.16-0241

37. Ochanji AA, Matu NK, Mulli TK (2017) Association of salivary RANKL and osteoprotegerin levels with periodontal health. Clin Exp Dent Res 3(2):4550. https://doi.org/https://doi.org/10.1002/cre2.49

38. Hassan SH, El-Refai MI, Ghallab NA, Kasem RF, Shaker OG (2015) Effect of periodontal surgery on osteoprotegerin levels in gingival crevicular fluid, saliva, and gingival tissues of chronic periodontitis patients. Dis Markers 2015:341259. https://doi.org/https://doi.org/10.1155/2015/341259

39. Ramesh A, Bhandary R, Thomas B, D'Souza SR, Kumari S (2013) Alkaline phosphatase-a diagnostic marker of periodontitis in postmenopausal women-a biochemical study. Nitte Univ J Health Sci 3(4):71-73

40. Badea V, Grigorian M, Nucă C, Amariei C, Martinescu A, Voineagu L (2013) Study regarding the use of salivary 8-hydroxideoxyguanosine and interleukin-1 gene polymorphism - as potential biomarkers in the diagnosis of aggressive periodontitis. Roman Rev Lab Med 21(1):75-82. https://doi. org/https://doi.org/10.2478/rrlm-2013-0020

41. Herr AE, Hatch AV, Giannobile WW, Throckmorton DJ, Tran HM, Brennan JS et al (2007) Integrated microfluidic platform for oral diagnostics. Ann N Y Acad Sci 1098:362-374. https://doi.org/https://doi.org/10.1196/annals.1384. 004

42. Christodoulides N, Floriano PN, Miller CS, Ebersole JL, Mohanty S, Dharshan $P$ et al (2007) Lab-on-a-chip methods for point-of-care measurements of salivary biomarkers of periodontitis. Ann N Y Acad Sci 1098(1):411-428. https://doi.org/https://doi.org/10.1196/annals.1384.035 
43. Gaertig C, Niemann K, Berthold J, Giel L, Leitschuh N, Boehm C et al (2015) Development of a point-of-care-device for fast detection of periodontal pathogens. BMC Oral Health 15(1):165. https://doi.org/https://doi.org/10. 1186/s12903-015-0155-y

44. J-i K, Abe K, Yatsushiro S, Bando M, Hiroshima Y, Nagata T et al (2012) Determination of calprotectin in gingival crevicular fluid by immunoassay on a microchip. Clin Biochem 45(15):1239-1244. https://doi.org/https://doi. org/10.1016/j.clinbiochem.2012.05.009

45. Imamura K, Takayama S, Saito A, Inoue E, Nakayama Y, Ogata Y et al (2015) Evaluation of a novel immunochromatographic device for rapid and accurate clinical detection of Porphyromonas gingivalis in subgingival plaque. J Microbiol Methods 117:4-10. https://doi.org/https://doi.org/10. 1016/j.mimet.2015.07.002

46. Mäntylä P, Stenman M, Kinane DF, Tikanoja S, Luoto H, Salo T et al (2003) Gingival crevicular fluid collagenase-2 (MMP-8) test stick for chair-side monitoring of periodontitis. J Periodontal Res 38(4):436-439. https://doi.org/ https://doi.org/10.1034/j.1600-0765.2003.00677.x

47. O'Brien-Simpson NM, Burgess K, Lenzo JC, Brammar GC, Darby IB, Reynolds EC (2017) Rapid chair-side test for detection of Porphyromonas gingivalis. J Dent Res 96(6):618-625. https://doi.org/https://doi.org/10.1177/ 0022034517691720

48. Rathnayake N, Gieselmann D-R, Heikkinen AM, Tervahartiala T, Sorsa T (2017) Salivary diagnostics - point-of-care diagnostics of MMP-8 in dentistry and medicine. Diagnostics 7(1):7. https://doi.org/https://doi.org/10.3390/ diagnostics7010007

49. Yee EH, Lathwal S, Shah PP, Sikes HD (2017) Detection of biomarkers of periodontal disease in human saliva using stabilized, vertical flow immunoassays. ACS sensors 2(11):1589-1593. https://doi.org/https://doi.org/ 10.1021/acssensors.7b00745

50. Bhakta SA, Borba R, Taba M Jr, Garcia CD, Carrilho E (2014) Determination of nitrite in saliva using microfluidic paper-based analytical devices. Anal Chim Acta 809:117-122. https://doi.org/https://doi.org/10.1016/j.aca.2013.11.044

51. Alhogail S, Suaifan G, Bizzarro S, Kaman WE, Bikker FJ, Weber K et al (2018) On site visual detection of Porphyromonas gingivalis related periodontitis by using a magnetic-nanobead based assay for gingipains protease biomarkers. Mikrochim Acta 185(2):149. https://doi.org/https://doi.org/10. 1007/s00604-018-2677-x

52. Wignarajah S, Suaifan GA, Bizzarro S, Bikker FJ, Kaman WE, Zourob M (2015) Colorimetric assay for the detection of typical biomarkers for periodontitis using a magnetic nanoparticle biosensor. Anal Chem 87(24):12161-12168. https://doi.org/https://doi.org/10.1021/acs.analchem.5b03018

53. Chepuri T, Gooty JR, Durvasala S, Palaparthi R (2015) Chair side diagnostic test kits in periodontics. Indian J Dental Advanc 7(1):41-46

54. Ravishankar P, Mithra D, Chakraborty P, Kumar A (2017) Chairside diagnostics in periodontics. SRM J Res Dent Sci 8(2):78. https://doi.org/ https://doi.org/10.4103/srmjrds.srmjrds_4_17

55. Malagi S (2012) Chairside diagnostic test kits in periodontics-a review. Int Arab J Dentistry 3(3)

56. Munjal S, Miethe P, Netuschil L, Struck F, Maier K, Bauermeister C (2007) Immunoassay-based diagnostic point-of-care technology for oral specimen. Ann N Y Acad Sci 1098(1):486-489. https://doi.org/https://doi.org/10.1196/ annals.1384.017

57. Phaechamud T, Thurein SM, Chantadee T (2018) Role of clove oil in solvent exchange-induced doxycycline hyclate-loaded Eudragit RS in situ forming gel. Asian J Pharm Sci 13(2):131-142. https://doi.org/https://doi.org/10.1016/ j.ajps.2017.09.004

58. Do M, Neut C, Metz H, Delcourt E, Siepmann J, Mäder K et al (2015) Eur J Pharm Biopharm 94:273-283. https://doi.org/https://doi.org/10.1016/j.ejpb. 2015.05.018

59. AlAhmari F, Ahmed HB, Al-Kheraif AA, Javed F, Akram Z (2019) Effectiveness of scaling and root planning with and without adjunct antimicrobial photodynamic therapy in the treatment of chronic periodontitis among cigarette-smokers and never-smokers: a randomized controlled clinical trial. Photodiagn Photodyn Ther 25:247-252. https://doi.org/https://doi.org/10. 1016/j.pdpdt.2019.01.006

60. Mundargi RC, Srirangarajan S, Agnihotri SA, Patil SA, Ravindra S, Setty SB et al. (2007) Development and evaluation of novel biodegradable microspheres based on poly(d,l-lactide-co-glycolide) and poly(epsiloncaprolactone) for controlled delivery of doxycycline in the treatment of human periodontal pocket: in vitro and in vivo studies. J Control Release 119(1):59-68. https://doi.org/https://doi.org/10.1016/j.jconrel.2007.01.008
61. Sah AK, Dewangan M, Suresh PK (2019) Potential of chitosan-based carrier for periodontal drug delivery. Colloids Surf B Biointerfaces 178:185-198. https://doi.org/https://doi.org/10.1016/j.colsurfb.2019.02.044

62. Do M, Neut C, Metz H, Delcourt E, Mäder K, Siepmann J et al (2015) In-situ forming composite implants for periodontitis treatment: how the formulation determines system performance. Int J Pharm 486(1-2):38-51. https://doi.org/https://doi.org/10.1016/j.ijpharm.2015.03.026

63. Agossa K, Lizambard M, Rongthong T, Delcourt-Debruyne E, Siepmann J, Siepmann F (2017) Physical key properties of antibiotic-free, PLGA/HPMCbased in-situ forming implants for local periodontitis treatment. Int J Pharm 521(1-2):282-293. https://doi.org/https://doi.org/10.1016/j.ijpharm.2017.02.039

64. Ranjan R, Patil SR, Veena H R (2017) Effect of in-situ application of simvastatin gel in surgical management of osseous defects in chronic periodontitis-a randomized clinical trial. J Oral Biol Craniofac Res 7(2):113118. https://doi.org/https://doi.org/10.1016/j.jobcr.2017.05.005

65. Kassem AA, Ismail FA, Naggar VF, Aboulmagd E (2014) Comparative study to investigate the effect of meloxicam or minocycline $\mathrm{HCl}$ in situ gel system on local treatment of periodontal pockets. AAPS PharmSciTech 15(4):10211028. https://doi.org/https://doi.org/10.1208/s12249-014-0118-7

66. Do MP, Neut C, Delcourt E, Seixas Certo T, Siepmann J, Siepmann F (2014) In situ forming implants for periodontitis treatment with improved adhesive properties. Eur J Pharm Biopharm 88(2):342-350. https://doi.org/https://doi. org/10.1016/j.ejpb.2014.05.006

67. Ruel-Gariepy E, Leroux J-C (2004) In situ-forming hydrogels—review of temperature-sensitive systems. Eur J Pharm Biopharm 58(2):409-426. https:// doi.org/https://doi.org/10.1016/j.ejpb.2004.03.019

68. Schmaljohann D (2006) Thermo-and pH-responsive polymers in drug delivery. Adv Drug Deliv Rev 58(15):1655-1670

69. Devasani SR, Dev A, Rathod S, Deshmukh G (2016) An overview of in situ gelling systems. Pharmaceut Biolog Evaluat 3(1):60-69

70. Schmaljohann D (2006) Thermo- and pH-responsive polymers in drug delivery. Adv Drug Deliv Rev 58(15):1655-1670. https://doi.org/https://doi. org/10.1016/j.addr.2006.09.020

71. Chakrabarty S, Nath B (2018) Oral in-situ gel for periodontitis: a review. World J Pharm Res 7(11):262-275. https://doi.org/https://doi.org/10.20959/ wjpr201811-12391

72. Kumbhar AB, Rakde AK, Chaudhari $P$ (2013) In situ gel forming injectable drug delivery system. Int J Pharm Sci Res 4(2):597-609

73. Sheshala R, Quah SY, Tan GC, Meka VS, Jnanendrappa N, Sahu PS (2019) Investigation on solution-to-gel characteristic of thermosensitive and mucoadhesive biopolymers for the development of moxifloxacin-loaded sustained release periodontal in situ gels. Drug Deliv Transl Res 9(2):434443. https://doi.org/https://doi.org/10.1007/s13346-018-0488-6

74. Bansal M, Mittal N, Yadav SK, Khan G, Gupta P, Mishra B et al (2018) Periodontal thermoresponsive, mucoadhesive dual antimicrobial loaded in-situ gel for the treatment of periodontal disease: preparation, in-vitro characterization and antimicrobial study. J Oral Biol Craniofac Res 8(2): 126-133. https://doi.org/https://doi.org/10.1016/j.jobcr.2017.12.005

75. Rajendran S, Kumar KS, Ramesh S, Rao SR (2017) Thermoreversible in situ gel for subgingival delivery of simvastatin for treatment of periodontal disease. Int J Pharm Investig 7(2):101-106. https://doi.org/https://doi.org/10. 4103/jphi.JPHI_26_17

76. Nasra MM, Khiri HM, Hazzah HA, Abdallah OY (2017) Formulation, in-vitro characterization and clinical evaluation of curcumin in-situ gel for treatment of periodontitis. Drug Deliv 24(1):133-142. https://doi.org/https://doi.org/10. 1080/10717544.2016.1233591

77. Bansal M, Mittal N, Yadav SK, Khan G, Mishra B, Nath G (2016) Clinical evaluation of thermoresponsive and mucoadhesive chitosan in situ gel containing levofloxacin and metronidazole in the treatment of periodontal pockets - a split-mouth, clinical study. J Pierre Fauchard Acad (India Section) 30(1):6-14. https://doi.org/https://doi.org/10.1016/j.jpfa.2016.10.003

78. Phaechamud T, Senarat S, Puyathorn N, Praphanwittaya P (2019) Solvent exchange and drug release characteristics of doxycycline hyclate-loaded bleached shellac in situ-forming gel and-microparticle. Int J Biol Macromol 135:1261-1272. https://doi.org/https://doi.org/10.1016/j.ijbiomac.2018.11.098

79. Phaechamud T, Lertsuphotvanit N, Praphanwittaya P (2018) Viscoelastic and thermal properties of doxycycline hyclate-loaded bleached shellac in situforming gel and-microparticle. J Drug Deliv Sci Technol 44:448-456. https:// doi.org/https://doi.org/10.1016/j.jddst.2018.01.021 
80. Phaechamud T, Setthajindalert O (2018) Antimicrobial in-situ forming gels based on bleached shellac and different solvents. J Drug Deliv Sci Technol 46:285-293. https://doi.org/https://doi.org/10.1016/j.jddst.2018.05.035

81. Mei L, Huang X, Xie Y, Chen J, Huang Y, Wang B et al (2017) An injectable in situ gel with cubic and hexagonal nanostructures for local treatment of chronic periodontitis. Drug Deliv 24(1):1148-1158. https://doi.org/https://doi. org/10.1080/10717544.2017.1359703

82. Phaechamud T, Chanyaboonsub N, Setthajindalert O (2016) Doxycycline hyclate-loaded bleached shellac in situ forming microparticle for intraperiodontal pocket local delivery. Eur J Pharm Sci 93:360-370. https:// doi.org/https://doi.org/10.1016/j.ejps.2016.08.034

83. Min KH, Jang E-Y, Lee HJ, Hwang Y-S, Ryu J-I, Moon J-H et al (2019) pHresponsive mineralized nanoparticles for bacteria-triggered topical release of antibiotics. J Ind Eng Chem 71:210-219. https://doi.org/https://doi.org/10. 1016/j.jiec.2018.11.027

84. Priyanka M, Meenakshi B (2011) Study of secnidazole-serratiopeptidase alginate/HPMC gels for periodontal delivery. Int J Pharm Technol Res 3(3): 1488-1494

85. Yadav S, Ahuja M, Kumar A, Kaur H (2014) Gellan-thioglycolic acid conjugate: synthesis, characterization and evaluation as mucoadhesive polymer. Carbohydr Polym 99:601-607. https://doi.org/https://doi.org/10 1016/j.carbpol.2013.08.068

86. Obaidat AA, Altamimi RM, Hammad MM (2010) Formulation and release of doxycycline HCL from an ion activatedin situgelling delivery system for the treatment of periodontal disease. J Appl Polym Sci 115(2):811-816. https:// doi.org/https://doi.org/10.1002/app.31204

87. Chichiricco PM, Riva R, Thomassin JM, Lesoeur J, Struillou X, Le Visage C et al (2018) In situ photochemical crosslinking of hydrogel membrane for guided tissue regeneration. Dent Mater 34(12):1769-1782. https://doi.org/ https://doi.org/10.1016/j.dental.2018.09.017

88. Saita M, Kaneko J, Sato T, Takahashi SS, Wada-Takahashi S, Kawamata R et al (2016) Novel antioxidative nanotherapeutics in a rat periodontitis model: reactive oxygen species scavenging by redox injectable gel suppresses alveolar bone resorption. Biomaterials 76:292-301. https://doi.org/https:// doi.org/10.1016/j.biomaterials.2015.10.077

\section{Publisher's Note}

Springer Nature remains neutral with regard to jurisdictional claims in published maps and institutional affiliations.

\section{Submit your manuscript to a SpringerOpen ${ }^{\circ}$ journal and benefit from:}

- Convenient online submission

- Rigorous peer review

- Open access: articles freely available online

High visibility within the field

- Retaining the copyright to your article

Submit your next manuscript at $\boldsymbol{\nabla}$ springeropen.com 